\title{
Identification of a repetitive sequence belonging to a PPE gene of Mycobacterium tuberculosis and its use in diagnosis of tuberculosis
}

Correspondence
Ranjana Srivastava
drranjana@yahoo.com

Received 18 October 2005 Accepted 28 April 2006

\author{
Ranjana Srivastava, ${ }^{1}$ D. Kumar, ${ }^{1}$ M. N. Waskar, ${ }^{1}$ Meera Sharma, ${ }^{2}$ \\ V. M. Katoch ${ }^{3}$ and Brahm S. Srivastava ${ }^{1}$ \\ ${ }^{1}$ Microbiology Division, Central Drug Research Institute, Lucknow 226001, India \\ ${ }^{2}$ Medical Microbiology, Postgraduate Institute of Medical Education and Research, Chandigarh, \\ India \\ ${ }^{3}$ Central JALMA Institute for Leprosy, Agra, India
}

A repetitive sequence specific to Mycobacterium tuberculosis was isolated from a $\lambda$ gt11 library of M. tuberculosis by DNA-DNA hybridization using genomic DNA of M. tuberculosis as probe followed by subtractive hybridization with a cocktail of other mycobacterial DNA. This led to identification of CD192, a 1291 bp fragment of M. tuberculosis containing repetitive sequences, which produced positive hybridization signals with $M$. tuberculosis DNA within 30 min. Nucleotide sequencing revealed the presence of several direct and inverted repeats within the $1291 \mathrm{bp}$ fragment that belonged to a PPE family gene (Rv0355) of M. tuberculosis. The use of CD192 as a DNA probe for the identification of $M$. tuberculosis in culture and clinical samples was investigated. The 1291 bp sequence was present in M. tuberculosis, Mycobacterium bovis and M. bovis BCG, but was not present in many of the other mycobacterial strains tested, including M. tuberculosis H37Ra. More than 300 clinical isolates of M. tuberculosis were probed with CD192, and the presence of the 1291 bp sequence was observed in all the clinical strains, including those lacking IS6110. The sequence displayed RFLP among the clinical isolates. A PCR assay was developed which detected $M$. tuberculosis with $100 \%$ specificity from specimens of sputum, cerebrospinal fluid and pleural effusion from clinically diagnosed cases of tuberculosis.

\section{INTRODUCTION}

One-third of the world's population is estimated to be infected with Mycobacterium tuberculosis. Hence, the identification of infected individuals comes as a first priority in strategies for tuberculosis control. The culture of mycobacteria from clinical samples is considered to be the most reliable technique and provides for definitive diagnosis of tuberculosis. Although $100 \%$ specific, it takes 6-8 weeks, owing to the slow growth of the organisms and the need for further biochemical testing (Heifets \& Good, 1994). On the other hand, nucleic acid probes coupled with amplification allow rapid and specific identification of $M$. tuberculosis in clinical samples (Pfyfer et al., 1996). Some of the probes include insertion elements (IS6110, IS1081), genes for

\footnotetext{
Abbreviations: ATT, antitubercular treatment; CSF, cerebrospinal fluid; $\mathrm{DR}$, direct repeat; IAC, internal amplification control; MPTR, major polymorphic tandem repeat; NPV, negative predictive value; PGRS, polymorphic GC-rich repetitive sequence; PPV, positive predictive value; TBM, tuberculous meningitis.

The GenBank/EMBL/DDBJ accession number for the CD192 sequence of $M$. tuberculosis is 810514 .
}

immunodominant antigens $(38 \mathrm{kDa}, 85$ protein complex, $30 / 32 \mathrm{kDa}, \mathrm{MPB} 64)$ and ribosomal sequences (16S and 23S rRNA) (Eisenach, 1999). These DNA probes are genus and species specific and utilize a wide array of sequences from a single-copy sequence to repetitive DNA elements. The repetitive DNA elements offer the advantage of sensitivity, and hence are ideal as diagnostic markers for strains.

Several repetitive DNA elements/sequences have been reported in M. tuberculosis, such as IS6110, the direct repeat (DR) cluster, IS1081, major polymorphic tandem repeats (MPTRs), polymorphic GC-rich repetitive sequences (PGRSs) and IS-like elements (Poulet \& Cole, 1995). IS6110 is typically present in multiple copies in M. tuberculosis and its species specificity, stability and RFLP make it a reliable diagnostic and epidemiological tool to fingerprint M. tuberculosis strains (Eisenach et al., 1990; Kolk et al., 1992). However, the discovery of several M. tuberculosis strains with one or no copy of IS6110 (Sahadevan et al., 1995; Van Soolingen et al., 1993) has shown that the repertoire of $M$. tuberculosis strains present all over the world may not be identified using a single repetitive element or probe. The 
search for novel DNA probes for M. tuberculosis remains a constant requirement.

The present investigation describes the identification of a repetitive sequence belonging to a PPE family gene of M. tuberculosis and its use in the molecular diagnosis of tuberculosis. The repetitive sequence was found useful in the identification of $M$. tuberculosis from culture and from clinical specimens of sputum, cerebrospinal fluid (CSF) and pleural effusion.

\section{METHODS}

Bacterial strains and clinical specimens. All mycobacterial and non-mycobacterial strains were obtained from the American Type Culture Collection and the Central JALMA Institute for Leprosy, Agra, India. Confirmed clinical isolates of M. tuberculosis were obtained from the All India Institute of Medical Sciences, New Delhi, the Postgraduate Institute of Medical Education and Research, Chandigarh, and the King George Medical College, Lucknow. Four clinical isolates of M. tuberculosis lacking IS6110 were obtained from the Tuberculosis Research Centre, Chennai. Clinical specimens (sputum, CSF and pleural effusion) were obtained from the King George Medical College, the Command Hospital and the Tuberculosis Hospital, all in Lucknow, and from the Ganesh Shanker Vidyarthi Medical College, Kanpur. Each specimen was streaked for culture on LJ slants and grown at $37^{\circ} \mathrm{C}$ for isolation of DNA. To isolate DNA, the clinical materials were transferred into microcentrifuge tubes and incubated for $10 \mathrm{~min}$ at $80^{\circ} \mathrm{C}$ to inactivate mycobacteria. Respiratory specimens, including sputum and pleural fluid, were digested and decontaminated by $\mathrm{N}$-acetyl-L-cysteine (NALC)/ $4 \% \mathrm{NaOH}$ and concentrated by centrifugation at $3000 \mathrm{~g}$ for $15 \mathrm{~min}$. The sediments were resuspended in $50 \mathrm{ml}$ phosphate buffer and recentrifuged at $3000 \mathrm{~g}$ for $15 \mathrm{~min}$ (Kent \& Kubica, 1985). The CSF specimens were directly suspended in $50 \mathrm{ml}$ phosphate buffer and centrifuged as described above. Part of the sample was streaked for culture on LJ slant and the rest of the sample was used for DNA extraction. The identification of M. tuberculosis and other nontubercular mycobacteria was done by biochemical tests (Koneman et al., 1997) and 16S rDNA sequencing (Kirschner et al., 1993).

Extraction of genomic DNA from culture and clinical samples. DNA from mycobacterial and non-mycobacterial strains was isolated by the method of Marmur (1961), with slight modification for mycobacterial DNA as described by Connell \& Ollar (1999). DNA from mycobacteria in clinical samples was isolated by the method described by Miyazaki et al. (1993).

DIG probe labelling and detection. Genomic DNA was passaged through a 25 gauge needle 8-10 times to shear DNA. Sheared DNA was denatured in a boiling-water bath for $10 \mathrm{~min}$ at $95^{\circ} \mathrm{C}$ followed by chilling in ice. Denatured DNA was labelled by the non-radioactive DIG DNA labelling and detection system (Boehringer Mannheim). The reaction was incubated at $37^{\circ} \mathrm{C}$ for $20 \mathrm{~h}$. Hybridized probes were immunodetected with anti-DIG-alkaline phosphatase and then visualized as blue spots with nitroblue tetrazolium (NBT) and 5bromo-4-chloro-3-indolyl phosphate (BCIP) substrates. Hybridization protocols described by Sambrook et al. (1989) were used.

Construction of genomic library and screening. A recombinant expression library of M. tuberculosis H37Rv DNA was constructed in the $\lambda$ gt11 vector, essentially as described by Young et al. (1985). All DNA manipulations were carried out by standard protocols (Sambrook et al., 1989). Briefly, genomic DNA was isolated from M. tuberculosis $\mathrm{H} 37 \mathrm{Rv}$, sheared to a mean length of $5 \mathrm{~kb}$ with serial passage through a 25 gauge needle, and treated with EcoRI methylase and $S$-adenosyl methionine to methylate the EcoRI sites. The DNA ends were then made flush with T4 DNA polymerase, and the DNA was purified. EcoRI linkers were added to the flush ends of the genomic DNA, and EcoRI sites were generated by digestion with EcoRI restriction enzyme. The EcoRI fragments thus generated were ligated in a small volume with EcoRI-digested dephosphorylated $\lambda$ gt11 DNA, and the library was packaged and amplified on Escherichia coli Y1088 at $42^{\circ} \mathrm{C}$, as described earlier (Young et al., 1985). The library had a titre of $1 \times 10^{10}$ p.f.u. $\mathrm{ml}^{-1}$ and contained approximately $60 \%$ recombinants with a mean size of $4 \mathrm{~kb}$.

The genomic library thus constructed was screened in two steps to select out $M$. tuberculosis-specific DNA sequences. The library was arrayed on a lawn of E. coli Y1088. The phage plaques were blotted onto a nitrocellulose membrane and probed first with a mixture of DIGlabelled genomic DNA of a clinical isolate of M. tuberculosis and the H37Rv strain. The plaques that produced hybridization signals intensely and rapidly within $30 \mathrm{~min}$ were picked and rescreened three times using the same genomic DNA probe. Finally, after tertiary screening, the plaques producing positive hybridization signals within $30 \mathrm{~min}$ were selected and subjected to subtractive screening in which the selected plaques were screened with a cocktail of mycobacterial DNA other than that of M. tuberculosis. This cocktail consisted of DIG-labelled genomic DNA of Mycobacterium avium-intracellulare, Mycobacterium fortuitum, Mycobacterium chelonae, Mycobacterium smegmatis and Mycobacterium phlei, mixed in equal concentration. After subtractive screening, the plaques hybridizing to $M$. tuberculosis but not to the cocktail of mycobacteria were chosen for further analysis.

PCR assay. The primers CD1 (5'-tgttgccgccgaaggtcatta- $\left.3^{\prime}\right)$ and CD2 (5'-gcagtggaaacatcggagtat- $\left.3^{\prime}\right)$ were designed from the $1291 \mathrm{bp}$ CD192 fragment (GenBank accession no. 810514) using DNASTAR and OMIGA softwares. CD1 and CD2 primers amplified a $777 \mathrm{bp}$ fragment. The PCR was performed in a $50 \mu \mathrm{l}$ reaction volume containing $15 \mathrm{mM} \mathrm{MgCl}, 5 \mu \mathrm{l} 10 \times$ PCR buffer (Promega; containing $100 \mathrm{mM}$ Tris/ $\mathrm{HCl}$, pH $9 \cdot 0\left(25^{\circ} \mathrm{C}\right), 500 \mathrm{mM} \mathrm{KCl}, 1 \%$ Triton $\mathrm{X}-100), 25$ pmol each primer, $200 \mu \mathrm{M}$ each deoxynucleotide triphosphate, and 1.5 U Taq DNA polymerase (Promega). The temperature regimen consisted of a denaturation cycle of $94^{\circ} \mathrm{C}$ for $5 \mathrm{~min}$ followed by $96^{\circ} \mathrm{C}$ for $1 \mathrm{~min}, 60^{\circ} \mathrm{C}$ for $1 \mathrm{~min}$ and $72^{\circ} \mathrm{C}$ for $1 \mathrm{~min}$, for 30 cycles. An elongation step of $72^{\circ} \mathrm{C}$ for 5 min ended the PCR. The amplified product was electrophoresed on a $1.2 \%$ agarose gel in $1 \times$ Tris/borate/EDTA (TBE) running buffer, stained in ethidium bromide and photographed under UV light. The primers T4 (5'-cctgcgagcgtaggcgtcgg- $\left.3^{\prime}\right)$ and T5 (5'-ctcgtccagcgccgcttcgg- $\left.3^{\prime}\right)$ were used for the detection of IS6110, which amplified a $123 \mathrm{bp}$ product (Eisenach et al., 1993). The PCR produtcs were purified from the gel by a gel extraction kit (Qiagen) and the nucleotide sequence was determined by automated sequencing on an $\mathrm{ABI}$ PRISM 310 Genetic analyser (Perkin Elmer Applied Biosystems). The sequence analysis was done using the DNASTAR program.

Southern hybridization. For Southern hybridization, the DNA was digested with appropriate restriction enzymes and electrophoresed through an agarose gel. After the electrophoresis was complete, the gel was stained with ethidium bromide and photographed. The DNA from the agarose gel was transferred onto a nitrocellulose membrane by the capillary transfer method after denaturation and neutralization of DNA within the agarose gel. After the transfer, the membrane was air-dried and baked at $80{ }^{\circ} \mathrm{C}$ under vacuum for $2 \mathrm{~h}$. The Southern blot after prehybridization at $42^{\circ} \mathrm{C}$ for $2-3 \mathrm{~h}$ was hybridized with DIG-labelled probe at $42^{\circ} \mathrm{C}$ for $8-16 \mathrm{~h}$ with continuous shaking, followed by detection. Hybridization conditions were essentially as described by Sambrook et al. (1989). DIG labelling and detection were done as described in the manufacturer's protocol (Boehringer Mannheim). 
RFLP analysis. The genomic DNA from clinical isolates of $M$. tuberculosis and non-tubercular mycobacteria was digested with the $S t u I$ restriction enzyme. The restricted DNA fragments were electrophoresed through an agarose gel $(0.8 \%, 0.5 \times \mathrm{TBE}$ buffer at $\left.\sim 1 \mathrm{~V} \mathrm{~cm}^{-1}\right)$. The DNA in the gel was denatured, and after neutralization was transferred onto a nitrocellulose membrane and hybridized with denatured DIG-labelled 1291 bp fragment.

Calculation of sensitivity and specificity. The sensitivity of the test was calculated as $[\mathrm{TP} /(\mathrm{TP}+\mathrm{FN})] \times 100 \%$, the specificity was calculated as $[\mathrm{TN} /(\mathrm{TN}+\mathrm{FP})] \times 100 \%$; the positive predictive value (PPV) was calculated as $[\mathrm{TP} /(\mathrm{TP}+\mathrm{FP})] \times 100 \%$, and the negative predictive value $(\mathrm{NPV})$ was calculated as $[\mathrm{TN} /(\mathrm{TN}+\mathrm{FN})] \times 100 \%$, where $\mathrm{TP}$ is true positive, $\mathrm{FN}$ is false negative, TN is true negative and FP is false positive.

\section{RESULTS AND DISCUSSION}

\section{Screening of the $\lambda$ gt11 M. tuberculosis library with genomic DNA of M. tuberculosis as probe}

The genomic $\lambda$ expression library was plated to $\sim 6 \times 10^{3}$ p.f.u. per plate on E. coli Y1088. Approximately 60000 recombinant plaques were screened, which represented the whole genomic library of $M$. tuberculosis. Fourteen plaques were selected as rapidly hybridizing clones after three successive screenings with DIG-labelled denatured chromosomal DNA of $M$. tuberculosis as probe. These 14 plaques produced hybridization signals within $30 \mathrm{~min}$ of detection. The clones were then subjected to subtractive screening with denatured chromosomal DNA from mycobacterial strains other than M. tuberculosis by DNA hybridization. This resulted in the elimination of six and the selection of eight recombinant plaques which hybridized with $M$. tuberculosis but not with denatured genomic DNA from M. aviumintracellulare, $M$. fortuitum, M. chelonae, M. smegmatis and M. phlei.

All eight clones contained inserts which were of different sizes. One of the clones, referred to as $\mathrm{C} 8$, produced hybridization signals within 10 min of detection. C8 contained an insert of $4 \cdot 2 \mathrm{~kb}$. The rapid-signal-producing sequences were mapped within a 1291 bp StuI-StuI fragment within the $4 \cdot 2 \mathrm{~kb}$ insert (Srivastava et al., 2000). The $1291 \mathrm{bp}$ fragment was designated CD192.

\section{Hybridization of CD192 with different mycobacterial strains and other pathogens}

The genomic DNA from different mycobacteria and other pathogens was cleaved with the restriction enzyme StuI, blotted onto nitrocellulose paper and hybridized with DIG-labelled CD192 by Southern as well as dot-blot hybridization. CD192 did not hybridize to DNA of different mycobacterial and non-mycobacterial strains, which included M. smegmatis, M. phlei, M. fortuitum, M. chelonae, Mycobacterium flavescens, Mycobacterium triviale, Mycobacterium duvali, Mycobacterium marinum, Mycobacterium gordonae, Mycobacterium kansasii, Mycobacterium avium, Mycobacterium intracellulare, Mycobacterium scrofulaceum, Mycobacterium xenopi, Mycobacterium aurum, Mycobacterium microti and Mycobacterium szulgai. Similarly, no hybridization was detected with Salmonella typhimurium, Staphylococcus aureus, Proteus vulgaris, Pseudomonas aeruginosa, Klebsiella pneumoniae, Enterobacter alginii, Vibrio cholerae, Bacillus subtilis, E. coli, salmon sperm DNA and human placental DNA.

\section{Presence of CD192 in clinical isolates of M. tuberculosis}

Mycobacterial cultures were raised from clinical samples and 366 cultures were obtained. Among these, 300 were identified as $M$. tuberculosis, while the rest were $M$. flavescens $(n=28), M$. fortuitum $(n=22)$, M. chelonae $(n=8), M$. triviale $(n=6)$ and M. kansasii $(n=2)$. Genomic DNA from each isolate was digested with the restriction enzyme StuI, blotted onto a nitrocellulose membrane and hybridized with DIG-labelled CD192 probe DNA. Upon hybridization, the probe detected only M. tuberculosis and no other mycobacteria. Essentially, all clinical M. tuberculosis isolates consistently displayed three bands; however, in 30\% of isolates, additional minor bands were obtained (Fig. 1). RFLP of M. tuberculosis clinical strains before and after prolonged passage in animals (mice) revealed identical patterns, suggesting that the element was quite stable in vivo. The 300 clinical isolates of M. tuberculosis were also analysed for the presence of IS6110 by PCR amplification of a $123 \mathrm{bp}$ fragment (Eisenach et al., 1993). Out of 300 isolates, 32 were devoid of IS6110 but contained CD192, as demonstrated by hybridization and later confirmed by PCR (data not shown).

\section{Nucleotide sequence of the CD192 DNA fragment}

The nucleotide sequence of CD192 was determined by the dideoxy chain-termination sequencing technique for both strands of CD192 (Biggins et al., 1983). The sequence has

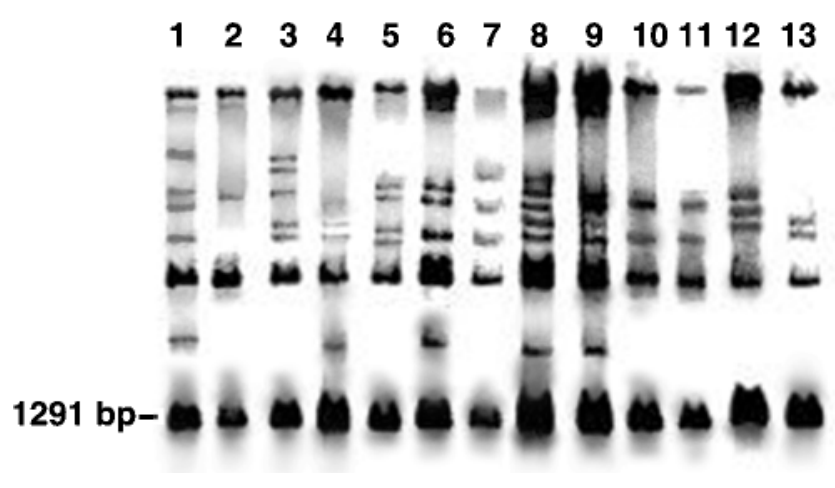

Fig. 1. RFLP analysis. The genomic DNA from M. tuberculosis H37Rv and clinical isolates of $M$. tuberculosis was isolated, digested with the restriction enzyme Stul and electrophoresed in a $0.8 \%$ agarose gel $(1 \times$ Tris/acetate/EDTA buffer). The fragments were electroblotted onto a nitrocellulose membrane and probed with DIG-labelled CD192 probe. Lane 2, M. tuberculosis H37Rv; lanes 1, 3-13, clinical isolates of M. tuberculosis. 
been submitted to GenBank with accession number 810514 . Computer-aided analysis of the nucleotide sequence and deduced protein sequence was performed using databases and programs provided by the National Institutes of Health (http://www.ncbi.nlm.nih.gov/BLAST/BLAST), as well as the programs of Chou \& Fasman (1978) and Hopp \& Woods (1981). The homology search of the CD192 sequence revealed it to be part of the PPE gene Rv0355c (424778$434677 \mathrm{bp}$ ) on the $M$. tuberculosis genome. However, a similar stretch on the M. tuberculosis genome is of $1286 \mathrm{bp}$ (Cole et al., 1998), whereas we have reported 1291 bp (Srivastava et al., 2000). That the 1291 bp is part of Rv0355 was also confirmed by the sequencing of neighbouring sequences present in the original $4 \cdot 2 \mathrm{~kb}$ insert of the C8 clone. Rv0355c is 9900 bp long and encodes a $327.03 \mathrm{kDa}$ protein of no known function. This glycine/asparagine-rich protein is a member of the M. tuberculosis PPE family, and contains large numbers of DRs and MPTRs (Cole et al., 1998). CD192 contained MPTRs (gccggtgttg or complement) characteristic of a PPE gene (Hermans et al., 1992; Table 1).

\section{Development of PCR-based assay}

Different sets of primers were designed within the $1291 \mathrm{bp}$ sequence of CD192 using the DNASTAR and OMIGA software packages and were subjected to PCR assay using target DNA of $M$. tuberculosis, atypical mycobacteria and nonmycobacterial species. The CD1 and CD2 primer pair was selected, which amplified 777 bp of DNA from $M$. tuberculosis, and this was visualized by agarose gel electrophoresis and DNA hybridization. A similar size fragment was amplified from Mycobacterium bovis and M. bovis BCG, but no amplification was observed with other mycobacterial and non-mycobacterial DNA, thus establishing the specificity of the primers for $M$. tuberculosis. An internal control of 461 bp was developed which could be amplified by the same CD1/CD2 primers for use as an internal amplification control (IAC). CD192 has two SmaI sites at 227 and 407 bp, and one NheI site at $541 \mathrm{bp}$. The removal of the NheI-SmaI fragment resulted in the deletion of $316 \mathrm{bp}$ from the 1291 bp fragment. When this deletion fragment served as template, CD1 and CD2 primers amplified a fragment of $461 \mathrm{bp}$ which was easily distinguishable from the $777 \mathrm{bp}$ fragment (Fig. 2). The deletion fragment could be seeded in the sample or used separately to rule out the presence of inhibitors in the sample in PCR reactions, which might otherwise lead to false-negative results.

\section{Evaluation of CD1/CD2 primers on clinical samples}

In this study, 200 clinical samples were selected to evaluate the CD192 probe, and were derived from patients who were clinically diagnosed cases of tuberculosis and responded to antitubercular treatment (ATT). The study protocol was as follows. Each collected sample was first streaked on LJ slants for culture and the rest was stored for PCR. These patients were immediately put on ATT. It is emphasized that the probe CD192 was evaluated on those samples whose donors were responding to ATT and that the samples were smear negative. Therefore, according to the study design, evaluation of the probe by PCR was carried out on clinically diagnosed culture-negative and culture-positive tuberculosis cases.

\section{Sputum samples}

Two hundred and fifty sputum samples were examined, which included samples from clinically diagnosed cases of tuberculosis $(n=105)$, and controls from other nonmycobacterial respiratory diseases $(n=80)$, mycobacteria other than tuberculosis (MOTT) $(n=20)$ and healthy persons $(n=45)$. Out of 105 samples, 65 were smear negative/culture positive and 40 were smear negative/culture negative. All culture-positive samples were PCR positive, and 30 out of 40 culture-negative samples were PCR

Table 1. Characteristics of DRs in the $1291 \mathrm{bp} \mathrm{Stul-Stul} \mathrm{DNA} \mathrm{fragment}$

The US patent no. of the $1291 \mathrm{bp}$ fragment is $6,114,514$.

\begin{tabular}{|lcll|}
\hline $\begin{array}{l}\text { Serial } \\
\text { no. }\end{array}$ & $\begin{array}{c}\text { Length } \\
(\mathbf{b p})\end{array}$ & \multicolumn{1}{c|}{ Sequence } & \multicolumn{1}{c|}{ Position (bp) } \\
\hline 1 & 26 & $\begin{array}{c}\text { CCG ATG TTG TTG TTG } \\
\text { CCG GTG TTG GC }\end{array}$ & 583,613 \\
2 & & TGA AGA AGC C & $200,1010,1256$ \\
3 & 10 & GCC CGT GTT G & $312,327,357$ \\
4 & 10 & TTG AGG ATG C & 349,379 \\
5 & 10 & CCG GTG TTG & $208,268,298,598$ \\
6 & 9 & CCG ATG TTG & $583,613,703,733,907$ \\
7 & 9 & GTT GAA GTC & $153,333,648,864$ \\
8 & 9 & GAA GAA GCC & $201,1011,1161,1257$ \\
9 & 9 & GTT GCC GGT & $264,513,594,624$ \\
10 & 9 & GCC GAC GTT & $447,672,687,807$ \\
\hline
\end{tabular}




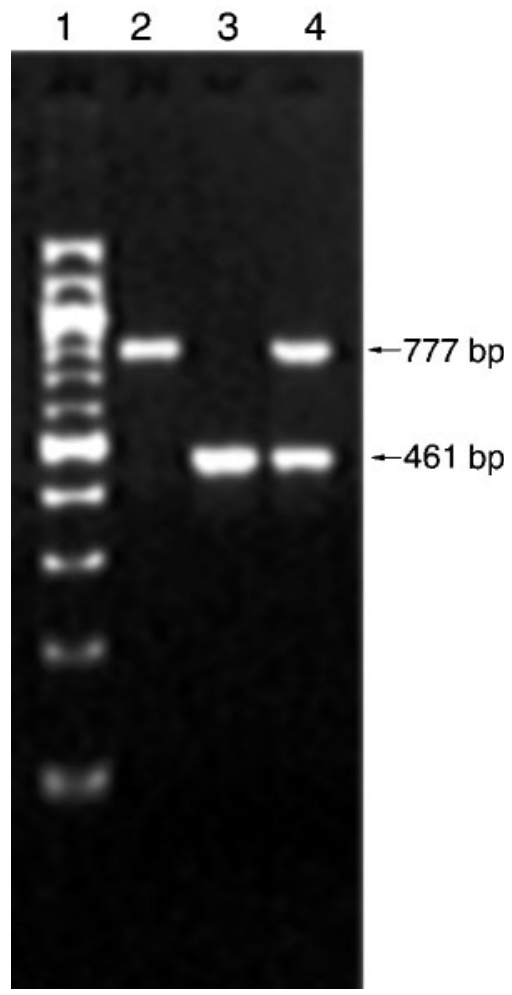

Fig. 2. $P C R$ amplification of $M$. tuberculosis and IAC DNA by CD1 and CD2 primers. Lane 1, 100 bp ladder (MBI Fermenta); lane 2, $777 \mathrm{bp}$ fragment amplified from M. tuberculosis; lane 3, 461 bp fragment of IAC DNA; lane 4, amplification of 777 and $461 \mathrm{bp}$ fragments from sample containing both $M$. tuberculosis and IAC DNA.

positive. All controls were negative by PCR (Table 2). Hence, sensitivity and specificity for PCR were found to be 90.4 and $100 \%$, respectively. In a study reported earlier, the probe CD192 was evaluated with CD1 and CD2 primers on sputum samples, and $81 \%$ sensitivity and $100 \%$ specificity for PCR was reported (Prasad et al., 2001).

\section{Tuberculous meningitis (TBM)}

One hundred and five CSF specimens were taken from 50 clinically diagnosed cases of TBM, and as a control, from 55 cases of non-tuberculous central nervous system (CNS) disease, including viral encephalitis and pyogenic meningitis. Patients with suspected TBM were those with fever and stiff neck for longer than 2 weeks. All CSF specimens from these patients had elevated leukocyte counts, polymorphonuclear pleocytosis, an elevated protein concentration ( $>60 \mathrm{mg} \mathrm{dl}^{-1} \mathrm{l}$ ) and CSF glucose concentration less than $60 \%$ of the amount of glucose in the serum (Priyadarshi, 1999). The CSF samples were analysed for detection of M. tuberculosis DNA by PCR using CD1 and CD2 primers. A 777 bp fragment was amplified in 35 out of 50 CSF specimens from clinically diagnosed TBM cases. Out of these 35, five were positive by culture. All controls were PCR negative. Thus, the sensitivity of the probe for detection of M. tuberculosis in CSF was $70 \%$, with $100 \%$ specificity (Table 2).

\section{Pleural fluid specimens}

The study was conducted on 45 cases of pleural effusion and 70 control subjects. Patients with pleural effusion presented fever, chest pain, dry cough and dyspnoea, with pleural fluid showing lymphocytosis, and the erythrocyte sedimentation rate (ESR) was raised. Test groups included clinically diagnosed cases of tuberculous pleural effusion $(n=45)$; the age of patients varied between 12 and 71 years. Of 45 cases, 11 were culture positive and 34 PCR positive. All culturepositive specimens were PCR positive. In the control group of patients $(n=70)$, none was culture or PCR positive. Thus the sensitivity of PCR was $77 \cdot 7 \%$, with $100 \%$ specificity (Table 2). In another isolated study, 22 specimens of pleural fluid were examined, out of which 15 were clinically suspected cases of pleural effusion and seven were of nontuberculous aetiology (control). All 15 samples were culture negative, while 10 were PCR positive. In the control group $(n=7)$, two were diagnosed cases of malignancy, being cases of adenocarcinoma confirmed by pleural fluid cytology; the

Table 2. Detection of M. tuberculosis in clinical specimens

\begin{tabular}{|c|c|c|c|c|c|c|c|c|}
\hline \multirow[t]{2}{*}{ Test } & \multicolumn{2}{|c|}{ Tuberculosis samples* } & \multicolumn{2}{|c|}{ Control samples } & \multirow{2}{*}{$\begin{array}{c}\text { Sensitivity } \\
(\%)\end{array}$} & \multirow{2}{*}{$\begin{array}{l}\text { Specificity } \\
(\%)\end{array}$} & \multirow{2}{*}{$\begin{array}{l}\text { NPV } \\
(\%)\end{array}$} & \multirow{2}{*}{$\begin{array}{l}\text { PPV } \\
(\%)\end{array}$} \\
\hline & Positive & Negative & Positive & Negative & & & & \\
\hline \multicolumn{9}{|l|}{ Sputum } \\
\hline Culture & 65 & 40 & - & 145 & $62 \cdot 9$ & 100 & $78 \cdot 3$ & 100 \\
\hline PCR & 95 & 10 & - & 145 & $90 \cdot 4$ & 100 & $92 \cdot 9$ & 100 \\
\hline \multicolumn{9}{|l|}{ CSF } \\
\hline Culture & 5 & 45 & - & 55 & $10 \cdot 0$ & 100 & $55 \cdot 0$ & 100 \\
\hline PCR & 35 & 15 & - & 55 & $70 \cdot 0$ & 100 & $78 \cdot 5$ & 100 \\
\hline \multicolumn{9}{|c|}{ Pleural fluid } \\
\hline Culture & 11 & 34 & - & 70 & $24 \cdot 4$ & 100 & $67 \cdot 3$ & 100 \\
\hline PCR & 35 & 10 & - & 70 & $77 \cdot 7$ & 100 & $87 \cdot 5$ & 100 \\
\hline
\end{tabular}

${ }^{\star}$ Specimens from clinically diagnosed cases of tuberculosis; all responded to ATT. 
remaining five were cases of pyogenic pleural effusion. One specimen of malignant pleural effusion gave a positive result by PCR, which is difficult to explain because the patient died shortly afterwards (Veerottam, 1999).

In this study, a new domain of repetitive sequence (CD192) has been identified within a PPE gene (Rv0355), as defined in the M. tuberculosis genome (Cole et al., 1998). Rv0355 is a member of the PPE gene family, characterized by the presence of the motif proline-proline-glutamic acid (PPE) at positions 7 and 9 in a highly conserved $\mathrm{N}$-terminal domain of 180 amino acids followed by a variable C-terminal region. The 68 members of the PPE family have been classified into three subfamilies; one of these subfamilies contains MPTR and PGRS sequences that are characterized by repeats of the motif AsnXGlyXGlyXAsnXGly. CD192 belongs to this family and contains several MPTRs (gccggtgttg), PGRSs (ttgccgccg), and several DRs, including a 26 bp sequence present in tandem copies separated by four bases. The MPTRs and PGRSs, originally described as non-coding repetitive sequences in the genome of $M$. tuberculosis (Hermans et al., 1992; Poulet \& Cole, 1995; Ross et al., 1992), have been exploited as epidemiological tools to differentiate M. tuberculosis strains (Braden et al., 1997; Ross et al., 1992; Van Soolingen et al., 1993).

Pulmonary tuberculosis is the most common presentation of tuberculosis, but it can affect any organ system, and clinical specimens other than sputum are known for the limited presence of bacilli. With the progression of disease, the presence of $M$. tuberculosis, the aetiological agent of tuberculosis, can be demonstrated microscopically in sputum, but the presence of bacilli in other forms of tuberculosis, such as TBM, pleural effusion or other extrapulmonary tuberculosis, is very difficult to detect because of low numbers of bacilli. The situation is aggrevated by the low culture positivity of these samples. The high prevalence of infection in an otherwise clinically undiagnosed population is also a very serious problem. In the management of tuberculosis, an assay which is rapid, specific and can detect few bacilli is very important. Therefore, sequence-specific amplification by PCR becomes the method of choice. If the target which is amplified or the probe which is used for hybridization contains repetitive sequences, the probability of adequate sensitivity is enhanced several-fold.

CD192 appears to fulfil these criteria. It contains repetitive sequences that produce hybridization signals within 10-30 min and is specific to M. tuberculosis. To assay its potential in diagnosis, a PCR assay was developed, and primers were used to detect $M$. tuberculosis in pulmonary, CSF and pleural-fluid specimens. The latter two contain very few bacilli and are usually culture negative, and specific diagnosis is urgently needed, because if untreated, the disease follows a chronic course that causes significant morbidity and mortality.

There are few DNA probes available for the detection of $M$. tuberculosis. The commercially available PCR test for the detection of M. tuberculosis complex marketed by Roche Diagnostic Systems amplifies a region of the 16S rDNA sequence that is genus specific and employs an M. tuberculosis complex-specific probe. The GenProbe amplified $M$. tuberculosis Direct (MTD) test employs the transcriptionmediated amplification of $16 \mathrm{~S}$ rRNA and is $M$. tuberculosis complex specific (Jonas et al., 1993; Scarparo et al., 2000). IS6110 has been used as a reliable, sensitive marker in the diagnosis of tuberculosis due to its high copy number, but has the limitation that it is not found in all M. tuberculosis clinical isolates (Sahadevan et al., 1995). CD192 demonstrated good sensitivity and specificity in sputum, CSF and pleural effusion, and was present in M. tuberculosis strains lacking IS6110. Thus, CD192 may be recommended for use in the identification of M. tuberculosis. The results of this investigation are based on long-term evaluation of pulmonary (sputum) and extrapulmonary tuberculosis patients, and reports good sensitivity and $100 \%$ specificity with pulmonary and extrapulmonary samples.

\section{ACKNOWLEDGEMENTS}

Thanks are due to the Director, Central Drug Research Institute, for facilities, the Department of Biotechnology, India, for partial support and evaluation of probe, and to Professor P. N. Tandon, because without his constructive criticism and initiative, the potential of CD192 in diagnosis would not have been established. Thanks are also due to the King George Medical College, the Sanjay Gandhi Post Graduate Institute of Medical Sciences, the Command Hospital and the Tuberculosis Hospital, Lucknow, and the Ganesh Shanker Vidyarthi Medical College, Kanpur, for providing the clinical specimens and participating in the evaluation studies. This is communication number 6449 of this Institute.

\section{REFERENCES}

Biggins, M. D., Gibson, T. J. \& Hong, G. F. (1983). Buffer gradient gels and $35 \mathrm{~S}$ label as an aid to rapid DNA sequence determination. Proc Natl Acad Sci U S A 80, 3963-3965.

Braden, C. R., Templeton, G. L., Cave, M. D. \& 7 other authors (1997). Interpretation of restriction fragment length polymorhism. Analysis of Mycobacterium tuberculosis isolates from a state with a large rural population. J Infect Dis 175, 1446-1452.

Chou, P. Y. \& Fasman, G. D. (1978). Prediction of the secondary structure of proteins from their amino acid sequence. Adv Enzymol 47, 45-148.

Cole, S. T., Brosch, R., Parkhill, J. \& 39 other authors (1998). Deciphering the biology of Mycobacterium tuberculosis from the complete genome sequence. Nature 393, 537-544.

Connell, N. D. \& Ollar, R. A. (1999). The mycobacterial and nocardial genomes and their isolation and manipulation. In Molecular Mycobacteriology: Techniques and Clinical Applications, pp. 87-107. Edited by R. A. Ollar \& N. D. Connell. New York: Marcel Dekker.

Eisenach, K. D. (1999). Molecular diagnostics. In Mycobacteria, Molecular Biology and Virulence, pp. 161-179. Edited by C. Ratledge \& J. Dale. Oxford, UK: Blackwell Science.

Eisenach, K. D., Cave, M. D., Bates, J. H. \& Crawford, J. T. (1990), Polymerase chain reaction amplification of a repetitive DNA sequence specific for Mycobacterium tuberculosis. J Infect Dis 161, 977-981. 
Eisenach, K. D., Cave, M. D. \& Crawford, J. T. (1993). PCR detection of Mycobacterium tuberculosis. In Diagnostic Molecular Microbiology: Principles and Applications, pp. 191-196. Edited by D. H. Persing, T. F. Smith, F. C. Tenover \& T. J. White. Washington, DC: American Society for Microbiology.

Heifets, L. B. \& Good, R. C. (1994). Current laboratory methods for the diagnosis of tuberculosis. In Tuberculosis, Pathogenesis, Protection and Control, pp. 85-109. Edited by B. R. Bloom. Washington DC: American Society for Microbiology.

Hermans, P. W. M., Van Soolingen, D. \& Van Embden, J. D. A. (1992). Characterization of a major polymorphic tandem repeat in Mycobacterium tuberculosis and its potential use in the epidemiology of Mycobacterium kansasii and Mycobacterium gordonae. J Bacteriol 174, 4157-4165.

Hopp, T. P. \& Woods, K. P. (1981). Prediction of protein antigenic determinants from amino acid sequences. Proc Natl Acad Sci U S A 78, 3824-3828.

Jonas, V., Alden, M. J., Curry, J. I., Kamisango, K., Knott, C. A., Lankford, R., Wolfe, J. M. \& Moore, D. F. (1993). Detection and identification of Mycobacterium tuberculosis directly from sputum sediments by amplification of rRNA. J Clin Microbiol 31, 2410-2416.

Kent, P. T. \& Kubica, G. P. (1985). Public Health Mycobacteriology: a Guide for the Level III Laboratory. Atlanta, GA: Centers for Disease Control.

Kirschner, P., Springer, B., Vogel, U., Meier, A., Wrede, A., Kiekenbeck, M., Bange, F. C. \& Bottger, E. C. (1993). Genotypic identification of mycobacteria by nucleic acid sequence determination. Report of a 2-year experience in a clinical laboratory. J Clin Microbiol 31, 2882-2889.

Kolk, A. H. J., Schuitema, A. R. J., Kuijper, S., van Leeuwen, J., Hermans, P. W. M., van Embden, J. D. A. \& Hartskeerl, R. A. (1992). Detection of Mycobacterium tuberculosis in clinical samples by using polymerase chain reaction and the non radioactive detection system. J Clin Microbiol 30, 2567-2575.

Koneman, E. W., Allen, S. D., Janda, W. M., Schreckenberger, P. C. \& Winn, W. C., Jr (1997). Mycobacteria. In Color Atlas and Textbook of Diagnostic Microbiology, 5th edn, pp. 893-952. Edited by E. W. Koneman, S. D. Allen, W. M. Janda, P. C. Schreckenberger \& W. C. Winn, Jr. Philadelphia, PA: Lippincott-Raven.

Marmur, J. (1961). A procedure for the isolation of deoxyribonucleic acid from microorganisms. J Mol Biol 3, 208-218.

Miyazaki, Y., Koga, H., Kohno, S. \& Kaku, M. (1993). Nested polymerase chain reaction for detection of Mycobacterium tuberculosis in clinical samples. J Clin Microbiol 31, 2228-2232.
Pfyfer, G. E., Kisling, P., Jahn, E. M. I., Martin, H., Salfinger, W. M. \& Weber, R. (1996). Diagnostic performance of amplified Mycobacterium tuberculosis direct test with cerebrospinal fluid, other nonrespiratory and respiratory specimens. J Clin Microbiol 34, 834-841.

Poulet, S. \& Cole, S. T. (1995). Repeated DNA sequences in mycobacteria. Arch Microbiol 163, 79-86.

Prasad, R., Lath, S. K., Mukerji, P. K., Agarwal, S. K. \& Srivastava, R. (2001). Clinical utility of polymerase chain reaction in patients of pulmonary tuberculosis. Indian J Tuberc 48, 135-138.

Priyadarshi, B. P. (1999). Evaluation of CSF by polymerase chain reaction analysis in diagnosis of tuberculous meningitis. MD thesis, GSVM Medical College, Kanpur.

Ross, B. C., Raios, K. \& Dwyer, B. (1992). Molecular cloning of a highly repeated DNA element from Mycobacterium tuberculosis and its use as an epidemiological tool. J Clin Microbiol 30, 942-946.

Sahadevan, R., Narayanan, S., Paramsivam, C. N., Prabhakar, R. \& Narayanan, P. R. (1995). Restriction fragment length polymorphism typing of clinical isolates of Mycobacterium tuberculosis from patients with pulmonary tuberculosis in Madras, India, by use of directrepeat probe. J Clin Microbiol 33, 3037-3039.

Sambrook, J., Fritsch, E. F. \& Maniatis, T. (1989). Molecular Cloning: a Laboratory Manual. 2nd edn. Cold Spring Harbor, NY: Cold Spring Harbor Laboratory.

Scarparo, C., Picoli, P., Rigon, A., Ruggiero, G., Scagnelli, M. \& Piersimoni, C. (2000). Comparison of enhanced Mycobacterium tuberculosis amplified direct test with COBAS amplicor Mycobacterium tuberculosis complex in respiratory and extrapulmonary specimens. J Clin Microbiol 38, 1559-1562.

Srivastava, R., Kumar, D. \& Srivastava, B. S. (2000). A Mycobacterium tuberculosis specific DNA fragment. US Patent, \# 6,114,514.

Van Soolingen, D., Dehass, P. E. W., Hermans, P. W. M., Groenen, P. M. A. \& Van Embden, J. D. A. (1993). Comparison of various repetitive DNA elements as genetic markers for strain differentiation and epidemiology of Mycobacterium tuberculosis. J Clin Microbiol 31, 1987-1995.

Veerottam, P. (1999). Value of polymerase chain reaction in pleural fluid in the diagnosis of tuberculous pleural effusion. MD Thesis, GSVM Medical College, Kanpur.

Young, R. A., Bloom, B. R., Grossinsky, C. M., Ivany, J., Thomas, D. \& Davis, R. W. (1985). Dissection of Mycobacterium tuberculosis antigens using recombinant DNA. Proc Natl Acad Sci USA 82, 2583-2587. 